\title{
Endoplasmic reticulum stress is involved in myocardial apoptosis of streptozocin-induced diabetic rats
}

\author{
Zhenhua Li*, Tao Zhang ${ }^{1} *$, Hongyan Dai ${ }^{2}$, Guanghui Liu, Haibin Wang, Yingying Sun, Yun Zhang \\ and Zhiming Ge
}

Department of Cardiology, Qilu Hospital of Shandong University, Key Laboratory of Cardiovascular Remodeling and Function Research, Ministry of Education and Ministry of Health, Jinan 250012, China

${ }^{1}$ Department of Orthopedic, Jinan Central Hospital, Medical School of Shandong University, Jinan, Shandong Province 250012, China

${ }^{2}$ Department of Cardiology, Qingdao's Municipal Hospital, Qingdao, Shandong Province 266021, China

(Correspondence should be addressed to Z Ge; Email: gezhiming@sdu.edu.cn)

* (Z Li and T Zhang contributed equally to this work)

\section{Abstract}

Apoptosis plays a critical role in the diabetic cardiomyopathy, and endoplasmic reticulum stress (ERS) is one of the intrinsic apoptosis pathways. Previous studies have shown that the endoplasmic reticulum becomes swollen and dilated in diabetic myocardium, and ERS is involved in heart failure and diabetic kidney. This study is aimed to demonstrate whether ERS is induced in myocardium of streptozotocin (STZ)-induced diabetic rats. We established a type 1 diabetic rat model, used echocardiographic evaluation, hematoxylin-eosin staining, and the terminal deoxy nucleotidyl transferase-mediated DNA nick-end labelin staining to identify the existence of diabetic cardiomyopathy and enhanced apoptosis in the diabetic heart. We

\section{Introduction}

In humans and animal models specific disease in the absence been described, and terme 2003, Avogaro et al. 2004 cardiomyopathy is attributed to abp organelles such (Feuvray 2004, Ta et al. 2006, Pereira et diabetic cardiomyopathyare not fully known, and appropriate approaches to minimize these risks are still being explored.

Apoptosis, as a regulated, energy-dependent, cell suicide mechanism has been reported to play a critical role in the development of diabetic cardiomyopathy (Cai \& Kang 2003, Dyntar et al. 2006, Ghosh \& Rodrigues 2006). Endoplasmic reticulum (ER) is an organelle involved in the intrinsic pathway of apoptosis (Ferri \& Kroemer 2001) and it is involved in several important functions such as the folding of secretory and membrane proteins. Various conditions can immunohistochemistr. and real-time PCR to analyze the hallmark of R 5 bat include glucose-regulated protein 78, CCAAr/enhancer-binding protein homologous protein $(\mathrm{CL}) \mathrm{O}$, caspase 12 . We found these hallmarks to have enhanced exprestion in protein and mRNA levels in diabetic mocardium. Aso, another pathway that can lead to ell death of RRS, c-Jun $\mathrm{NH}_{2}$-terminal kinase-dependent pat was also activated in diabetic heart. Those results suggested that 2 RS was induced in STZ-induced diabetic myocardium, and ERS-associated apoptosis occurred in physiology of diabetic cardiomyopathy.

mar of Endocrinology (2008) 196, 565-572

disturb the functions of the ER and result in ER stress (ERS). These conditions include ER-Ca ${ }^{2+}$ depletion, ischemia, hypoxia, exposure to free radicals, elevated protein synthesis, hyperhomocysteine, and gene mutation. Several signaling pathways are initiated to cope with ERS, which are designated as the unfolded protein response (UPR; Bernales et al. 2006). One major pathway of UPR is to increase regulation of the expression of ER-localized molecular chaperons, such as glucose-regulated protein 78 (GRP78), which can contribute to repairing unfolded proteins. The early UPR enhances cell survival by ensuring that the adverse effects of ERS are dealt with in a timely and efficient manner. When ERS conditions persist, initiation of apoptotic processes are promoted by transcriptional induction of CCAAT/enhancer-binding protein (C/EBP) homologous protein (CHOP/GADD153; Wang et al. 1996), the caspase12-dependent pathway (Hetz et al. 2003), and activation of the c-Jun $\mathrm{NH}_{2}$-terminal kinase (JNK)-dependent pathway (Hotamisligil 2005).

Evidence has demonstrated that apoptosis initiated by the ERS was involved in the pathogenesis of heart failure and 
diabetic kidney (Okada et al. 2004, Hayden et al. 2005, Nakatani et al. 2005). The ERS has been found in cultured hepatocytes, monocytes, and smooth muscle cells with both glucose and glucosamine independent of increased O-linked glycosylation (Werstuck et al. 2006). Actually, hyperglycemia environment also induces several conditions that can invoke ERS. It was reported that the $\mathrm{ER} \mathrm{Ca}^{2+}$ store and rates of $\mathrm{Ca}^{2+}$ release and resequestration into ER were found depressed in diabetic rat myocytes because hyperglycemia inhibits the capacitative calcium entry, and there are direct correlations existing between hyperglycemia and oxidative stress and hyperglycemia and hyperhomocysteine (Choi et al. 2002, Pang et al. 2002, King \& Loeken 2004, Wijekoon et al. 2007).

Ultrastructural analysis found ER swelling and dilation in the diabetic model myocardium (Jackson et al. 1985, Bhimji et al. 1986). Dilated ER is a change in morphology that suggests ERS (Riggs et al. 2005, Borradaile et al. 2006, Tiwari et al. 2006), but the relationship between ERS and diabetic cardiomyopathy is unknown.

\section{Materials and Methods}

\section{Animals}

Thirty male Wistar rats from animal center of Shandong University ( 8 weeks of age; mean body weight $280 \pm 10 \mathrm{~g}$ ) were used. The rats were housed by cage and had free acce to normal rat diet and tap water of the center. They maintained under conditions of standard lighting (alternat $12 \mathrm{~h}$ light: $12 \mathrm{~h}$ darkness cycle), temperature $\left(22 \pm 0.5^{\circ} \mathrm{C}\right.$ and humidity $(60 \pm 10 \%)$ for at least 1 we experiments. All experiments were carried with the recommendations of the Univer Animal Welfare (UFAW) Handbog Management of Laboratory Animal

20 were given a single i.p. dose

(STZ; S0130 Sigma-Aldrich ssolved $4 \cdot 5)$ ), while the remaining ats trere given same dosage of citrate buffer $(\mathrm{pH} 4 \cdot 5)$. Diabete ys confirmed by measuring the venous circulating plasm concentrations of glucose. Seven days post-S Z injectron, blood samples were obtained from the rat the vein 12 of fasting, and the glucose concentration watermine with an automatic analyzer (One Touch Sur Ste Meter, LifeScan, CA, USA). Nineteen rats reached the diatetic at standard of a fasting blood glucose level higher than $300 \mathrm{mg} / \mathrm{dl}$, while the value in the control group of rats injected with saline ranged from 90 to $130 \mathrm{mg} / \mathrm{dl}$. Due to infection, an STZ-diabetic rat died after 2 weeks and another STZ-diabetic rat died after 10 weeks. Sixteen weeks post-saline and STZ injection, 17 STZdiabetic rats were left, while the control group survived.

\section{Echocardiographic evaluation}

During the 16 weeks of study, before killing, each rat was anesthetized with ketamine $\mathrm{HCl}(50 \mathrm{mg} / \mathrm{kg})$ and xylazine
$(10 \mathrm{mg} / \mathrm{kg})$ that was placed in the left lateral decubitus position. The chest of the rat was shaved and a layer of acoustic coupling gel was applied to the thorax, twodimensional and M-mode echocardiography was performed using a commercially available $12-\mathrm{MHz}$ linear array transducer system and echocardiogram machine (Sonos 5500, HP, Boston, MA, USA). The M-mode recordings obtained were of the left ventricle at the level of the mitral valve in the parasternal view using two-dimensional echocardiographic guidance in both the short- and long-axis views. Pulsed wave Doppler was used to examine mitral diastolic inflow from the apical four-chamber view. For each measurement, data from three onserutive cardiac cycles were averaged. All measurem made from digital images captured at the time study by use of inherent analysis software (Sonos 550 so ftwate pacage). The results are presented in Table

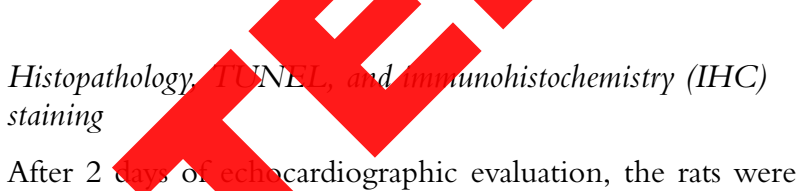
anesthetized again, the hearts removed and sliced transversely, and eight diabenc and five control hearts were fixed in heutral bufered formalin, and then paraffin-embedded for micro pic evaluation. Eight diabetic and five control hearts were rozen at $-80^{\circ} \mathrm{C}$ for the use of western blot and teal-time PCR. The experimental procedures adhered to the ines of Shandong University's Code for the Care and Use of Animals for Scientific Purposes. All studies were performed with an observer overlooking the study groups to which the animals had been assigned. Hearts embedded in paraffin were sectioned at $5 \mu \mathrm{m}$ and studied with hematoxylin-eosin stain, a terminal deoxynucleotidyl transferase (TDT)-mediated DNA nick-end labeling (TUNEL) assay kit, and IHC. The sections were examined using light microscopy and analyzed with a computer-assisted color image analysis system (Image-ProPlus 5.1, Media Cybernetics, Silver Spring, MD, USA).

Assessment for apoptosis was conducted using a commercially available TUNEL assay kit (code number KGA 703, Keygen Biotechnology, Nanjing, China). Briefly, sections

Table 1 The sequence for each primer and product length

\begin{tabular}{|c|c|c|}
\hline & Sequence & Length (bps) \\
\hline GRP78 & $\begin{array}{l}\text { F: 5' TCAGCCCACCGTAACAAT 3' } \\
\text { R: } 5^{\prime} \text { CAAACTTCTCGGCGTCAT 3' }\end{array}$ & 275 \\
\hline Caspase12 & $\begin{array}{l}\text { F: } 5^{\prime} \text { GGAAGGTAGGCAAGAGT 3' } \\
\text { R: } 5^{\prime} \text { GTAGAAGTAGCGTGTCATA } 3^{\prime}\end{array}$ & 179 \\
\hline $\mathrm{CHOP}$ & $\begin{array}{l}\text { F: } 5^{\prime} \text { AGCTGAGTCTCTGCCTTTCG } 3^{\prime} \\
\text { R: } 5^{\prime} \text { TGTGGTCTC TACCTCCCTGG } 3^{\prime}\end{array}$ & 456 \\
\hline GAPDH & $\begin{array}{l}\text { F: 5' GTCGGTGTCAACGGATTTG 3' } \\
\text { R: 5' ACAAACATGGGGGCA TCAG 3' }\end{array}$ & 397 \\
\hline
\end{tabular}

The primers' sequence and product length designed for GRP78, caspase12, $\mathrm{CHOP}$ and GAPDH. www.endocrinology-journals.org 
were deparaffinized, digested with proteinase $\mathrm{K}(20 \mu \mathrm{g} / \mathrm{ml})$, at room temperature for $15 \mathrm{~min}$, and soaked in PBS for $5 \mathrm{~min}$. Each section was covered with a TDT enzyme solution containing $45 \mu \mathrm{l}$ equilibration buffer, $1 \mu \mathrm{l}$ biotin-11-dUTP, $4 \mu \mathrm{T}$ TDT enzyme, and incubated for $1 \mathrm{~h}$ at $37^{\circ} \mathrm{C}$ in a humidified chamber. The sections were immersed in stop buffer to terminate the enzymatic reaction, and then gently rinsed with PBS. A $50 \mu \mathrm{l}$ streptavidin-horseradish peroxidase (HRP) solution containing $0.25 \mu \mathrm{l}$ streptavidin-HRP and $49 \cdot 75 \mu \mathrm{l}$ PBS was then applied to each section, and then incubated at room temperature for $30 \mathrm{~min}$ in the darkness. Slides were washed in PBS and exposed to 3,3-diaminobenzidine (DAB) + chromogen (code number ZLI-9032, Zhongshan Golden Bridge Biotechnology, Beijing, China) for 5-7 min. The slides were then rinsed in water and counterstained with hematoxylin. Then the sections were examined using light microscopy. Sections incubated with PBS, instead of TDT enzyme solution, served as the negative controls.

The tissue expression of GRP78 was assessed immunohistochemically using antibody (code number sc1611, Santa Cruz Biotechnology, Santa Cruz, CA, USA). After deparaffinization, endogenous peroxidase activity was quenched with 30\% methanol and $0 \cdot 3 \%$ hydrogen PBS. The slides were then boiled in citrate buffer with microwaves. After blocking nonspecific binding with 5\% BSA, the slides were incubated with primary antibodies overnight at $4{ }^{\circ} \mathrm{C}$ (dilutions for antiGRP78 1:400). The following day, the sections we thoroughly washed in PBS and incubated with a per oxidase-conjugated polymer that carries antibodies to goat (1:200) immunoglobulin (code number ZB-230

shan Golden Bridge Biotechnology) for $30 \mathrm{~min}$ with PBS, the sections were exposed to DAB for $7 \mathrm{~min}$. The slides were rinsed in wate with hematoxylin. The immunohistoe samples was performed at differen technical personnel. The section incubated with PBS, instead of the primary antiserum, se as the negati controls.

\section{Western blot}

Protein from the art the diatic and normal rat was extracted for westetn blot use The tissue samples were homogenized in a ysis uffer $(0 \cdot 1 \mathrm{~mol} / 1 \mathrm{NaCl}, 0 \cdot 01 \mathrm{M}$ Tris$\mathrm{HCl}(\mathrm{pH} \mathrm{7.5),} 1 \mathrm{mM}$ EDTA, and $1 \mu \mathrm{g} / \mathrm{ml}$ Aprotinin) and then the homogenates were centrifuged at $7000 \boldsymbol{g}$ for $15 \mathrm{~min}$ at $4{ }^{\circ} \mathrm{C}$. The supernatants were used as protein samples. We used a Bradford assay (Bio-Rad Laboratories) to determine each sample's protein concentration, then performed western blot analysis with a 5\% acrylamide stacking gel and a $14 \%$ acrylamide resolving gel, and $60 \mu \mathrm{g}$ protein was subjected to gel electrophoresis. Proteins from the gel to nitrocellulose membranes (code number LC2006, Invitrogen) was performed for $50 \mathrm{~min}$ at $120 \mathrm{~V}$. Nonspecific protein binding to the nitrocellulose membrane was reduced by pre-incubating the membrane with blocking buffer (5\% nonfat dry milk,
$2.7 \mathrm{mM} \mathrm{KCl}, 137 \mathrm{mM} \mathrm{NaCl}, 8 \mathrm{mM} \mathrm{NaHPO}, 1.4 \mathrm{mM}$ $\mathrm{KPO}_{4}$, and $0 \cdot 1 \%$ Tween 20) for $2 \mathrm{~h}$ at room temperature. Then incubation with the monoclonal antibody anti- $\beta$ actin (1:1000 diluted in blocking buffer, Zhongshan Golden Bridge Biotechnology), anti-GRP78 (1:500), anti-CHOP (1:500, SC-7531, Santa Cruz Biotechnology), anti-caspase12, (1:1000, SC-1050, Santa Cruz Biotechnology), and antiJNK1 (1:2000, SC-474, Santa Cruz Biotechnology) were performed overnight at $4{ }^{\circ} \mathrm{C}$. Then incubation with secondary antibody (anti-rabbit, anti-rat, and anti-goat $\operatorname{IgG}$ conjugated to HRP, in blocking buffer 1:1000, Zhongshan Golden Bridge Biotechnology) lasted $1 \mathrm{~h}$, also at room temperature. The reaction was isulized by chemiluminescence (Enhanced Chennlunimescent Kit, ECL, Amersham). The film was canted with an imaging densitometer (fluorchem HA IS- A 900, CA, USA), and the optical density quantified using Multi-Analyst software.

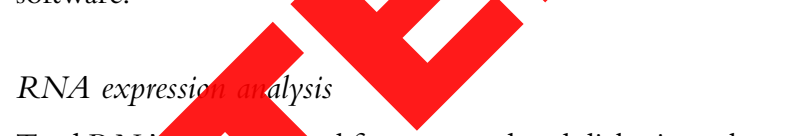
Total RNA os extracted from normal and diabetic rat hearts by the single-step aci-guanidium-phenol-chloroform method (21) using Trizol reagent (code number 15596-026, Inv itrogen) a colding to the manufacturer's instructions. The RN was quntified by u.v. spectrophotometry at $260 / 280 \mathrm{~nm}$ ad diluted to $1 \mu \mathrm{g} / \mu \mathrm{l}$ in diethyl pyrocarbonate (DEPC)-treated water. The RNA samples were analyzed by hyde-agarose gel electrophoresis, and integrity was nfirmed by visualization of $18 \mathrm{~S}$ and $28 \mathrm{~S}$ rRNA bands. First-strand cDNA was synthesized in a $40 \mu \mathrm{l}$ total volume by using oligo (dT) 12-18 primer and Moloney murine leukemia virus (MMLV) reverse transcriptase (code number $\mathrm{m} 1701$, Promega). To reduce pipetting variation, a master RT mixture was prepared and added to each of the different RNA samples. Briefly, reverse transcription was performed in a $40 \mu \mathrm{l}$ volume mixture made up of $6 \mu \mathrm{l}$ total RNA, $2 \mu \mathrm{l}$ Olig (dT), $8 \mu 1$ reverse-transcription buffer, $2 \mu 12.5 \mathrm{mM}$ dNTP mixture, $2 \mu \mathrm{l}$ MMLV reverse transcriptase, and $20 \mu \mathrm{l}$ DEPCtreated water. The condition was incubated at $37^{\circ} \mathrm{C}$ for $1 \mathrm{~h}$ and then heated at $95^{\circ} \mathrm{C}$ for $5 \mathrm{~min}$. The cDNA was stored at $-20^{\circ} \mathrm{C}$ for use. The sequence for each primer and product are presented in Table 1.

Real-time PCR was carried out using the real-time detection system (ABI Prism 7000, Foster City, CA, USA) with a real-time PCR master mix (code number: QPK-201, Toyobo, Japan) that contains SYBR-Green I as fluorescent dye enabling real-time detection of PCR products. The protocol was followed according to the manufacturer's instructions. A $50 \mu \mathrm{l}$ volume mixture was made up of $1 \mu \mathrm{l}$ sense primer $(10 \mu \mathrm{M}), 1 \mu \mathrm{l}$ antisense primer $(10 \mu \mathrm{M}), 25 \mu \mathrm{l}$ real-time PCR master mix, $18 \mu \mathrm{l}$ (DEPC)-treated water, and $5 \mu \mathrm{cDNA}$. The cycling conditions were $95^{\circ} \mathrm{C}$ for $3 \mathrm{~min}$, followed by 40 cycles at $94^{\circ} \mathrm{C}$ for $30 \mathrm{~s}, 60^{\circ} \mathrm{C}$ for $30 \mathrm{~s}$, and $72{ }^{\circ} \mathrm{C}$ for $60 \mathrm{~s}$. For quantification, the mRNA of GRP78, $\mathrm{CHOP}$, and caspase 12 gene was normalized to the mRNA of 
the internal standard gene glyceraldehyde-3-phosphate dehydrogenase.

\section{Statistical analysis}

All the results are expressed as mean \pm s.D. The individual groups were tested for differences by using one-way ANOVA repeated measurements, followed by independent samples $t$-test. Differences were considered as being statistically significant at ${ }^{\#} P<0 \cdot 05$.

\section{Results}

\section{Establishment of the diabetic cardiomyopathy model}

The body weight and blood glucose levels are shown in Fig. 1A and B. The left ventricular systolic function parameters, fractional shortening (\%), and ejection fraction of the diabetic animals were significantly reduced when compared with their week 1 levels and normal animals at 16 weeks (Table 2). Left ventricular diastolic function variables expressed by the $E$-wave (early diastolic filling and early peak velocity) and $A$-wave (late atrial filling and atrial peak velocity) differed significantly in diabetic animals when compared with their week 1 levels and normal animals at 16 weeks. A significant decrease in $E$-wave velocity, significant increase in the $A$-wave velocity, a significant decrease in the $E / A$ ratio was found, after 16 we in the diabetic groups, with a significant decr fractional shortening and ejection fraction. Th diastolic performance is thought to result frop compliance. With hematoxylin-eosin found that diabetic cardiac muscle fib many of them were collapsed. Di

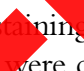
ning (Fis. 2), we yocardiun showed fibrosis and extensive focal coalescevareas of chemic myocyte degeneration in the subendocadial, subepicardal region, and papillary muscles of the m ardin The above results certified that our diabetic rats suffored diabetic cardiomyopathy.

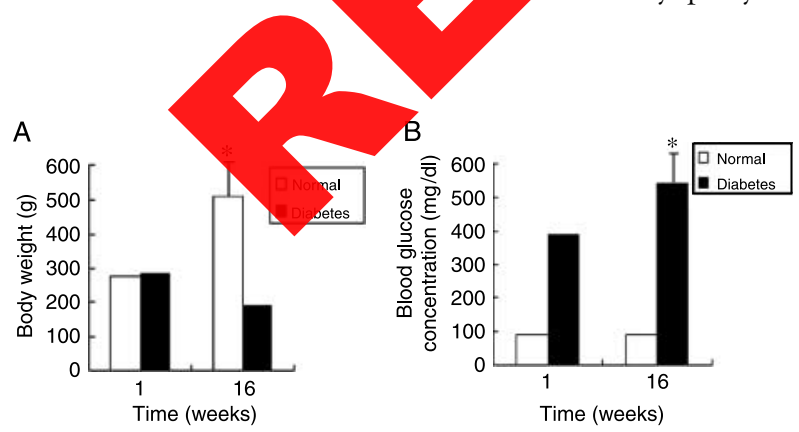

Figure 1 (A) Body weight significantly decreased in diabetic rats whereas it significantly increased in normal rats at 16 weeks when compared with their week 1 levels. (B) Blood glucose levels in the diabetic animals have shown a significant raise at 1 week after diabetes induction, and continued to 16 weeks compared with the normal rats. ${ }^{*} P<0.05$ versus normal rats.
Localization of apoptosis by TUNEL assay and IHC analysis of GRP78 distribution

To assess whether diabetes results in apoptotic cell death in the diabetic myocardium, the tissue sections were labeled with an in situ TUNEL assay. Apoptosis was observed in both the cardiomyocyte and endothelium of the diabetic heart (Fig. 3A). Estimation of cardiac apoptosis revealed a nearly sevenfold increase in TUNEL-positive nuclei in diabetic hearts (Fig. 3C). As can be seen in Fig. 3B, immunochemistry studies showed that GRP78 was abundantly expressed in the myocardium from diabetic rats. In contrast, normal rats exhibited modest or weak immunoreactivity for this molecule. We also found that in diabetic myocardium, the increase of GRP78 positive of apoptotic cells (Fig. 3C arallo vith the increase Western blot analysi of 78,30 , and 46kDa respectivery, and two bands between 30 and $50 \mathrm{kDa}$ for caspase 12. The densitometric analysis of bands for GP P78.CHOP, caspase12, and JNK1 revealed a significant $0.05)$ in rease in relative protein content in myocardium diabetic ats in comparison with those from normal rats. This mean CHOP was induced, and caspase12 and JNK pathway were activated in the diabetic heart.

RT-PCR analysis of GRP78, CHOP, and caspase 12 expression

Changes in RNA expression of GRP78, CHOP, and caspase12 were quantified by RT-PCR in control and diabetic rat hearts (Fig. 5). Expressions of GRP78, CHOP, and caspase12 were significantly increased in the diabetic heart $(P<0 \cdot 05)$, paralleled with their enhanced protein expression.

\section{Discussion}

Diabetic cardiomyopathy is characterized by both systolic and diastolic dysfunction (Galderisi 2006). In this current study, we established type 1 diabetic rat model and used both echocardiographic evaluation and histological changes with hematoxylin-eosin staining to identify the existence of diabetic cardiomyopathy in them. The result of TUNEL staining of the myocardium suggested that more cardiomyocytes and endothelial cells were apoptotic in the diabetic hearts than in normal hearts. We demonstrated that GRP78 has enhanced expression that paralleled with increased apoptotic cells. Also, three hallmarks of ERS-induced apoptosis CHOP, caspase12, and JNK1 were found to have increased in protein and mRNA levels. These findings suggest that ERS was induced in our experimental paradigm, and ERS-associated apoptosis pathway was activated. To our 
Table 2 Transmitral Doppler flow velocity recordings in normal $(n=10)$ and diabetic $(n=17)$ rats at weeks 1 and 16 . Results shown are mean \pm s.D.

\begin{tabular}{|c|c|c|}
\hline & Week 1 & \\
\hline & Normal & Diabetic \\
\hline$E$ & $53 \cdot 25 \pm 5 \cdot 57$ & $52 \cdot 24 \pm 5 \cdot 62$ \\
\hline$A$ & $27 \cdot 34 \pm 6 \cdot 57$ & $31 \cdot 09 \pm 5 \cdot 65$ \\
\hline$E / A$ & $2 \cdot 11 \pm 0 \cdot 31$ & $1 \cdot 76 \pm 0 \cdot 13$ \\
\hline Eat & $28 \cdot 15 \pm 6 \cdot 45$ & $27 \cdot 89 \pm 5 \cdot 89$ \\
\hline Edt & $48 \cdot 34 \pm 6 \cdot 59$ & $47 \cdot 23 \pm 7 \cdot 12$ \\
\hline EF & $61 \cdot 34 \pm 7 \cdot 76$ & $61 \cdot 57 \pm 4 \cdot 42$ \\
\hline FS & $27 \cdot 39 \pm 3 \cdot 19$ & $27 \cdot 18 \pm 4 \cdot 67$ \\
\hline LVSD (mm) & $1 \cdot 01 \pm 0 \cdot 39$ & $1 \cdot 03 \pm 0 \cdot 42$ \\
\hline LVDD (mm) & $4 \cdot 92 \pm 0.43$ & $4 \cdot 98 \pm 0 \cdot 4$ \\
\hline
\end{tabular}

Week 16

\begin{tabular}{r} 
Normal \\
\hline $55 \cdot 34 \pm 5 \cdot 67$ \\
$28 \cdot 45 \pm 6 \cdot 67$ \\
$2 \cdot 05 \pm 0 \cdot 45$ \\
$27 \cdot 45 \pm 6 \cdot 34$ \\
$48 \cdot 98 \pm 7 \cdot 01$ \\
$60 \cdot 56 \pm 5 \cdot 10$ \\
$28 \cdot 16 \pm 4 \cdot 08$ \\
$1 \cdot 12 \pm 0 \cdot 43$ \\
$5 \cdot 42 \pm 0 \cdot 51$
\end{tabular}

$E$, peak early transmitral filling velocity during early diastole; $A$, peak transmitral atrial filling velocity during late diastole; deceleration time of $E$-wave; EF, ejection fraction; FS, fractional shortening; LVSD, ventricular systolic dysfunction; ${ }^{*} P<0 \cdot 05$ compared to week 1 data. ${ }^{\dagger} P<0 \cdot 05$ compared to normal rats.

knowledge, this is the first study that implicates that ERS plays a role in the pathophysiology of diabetic cardiomyopathy.

As a comprehensive consequence of abnormal cellular metabolism and gene expression in response to hyperglycemia, cell death has been considered to be the important cause of diabetic cardiomyopathy. Because myocytes rarely proliferate in adult cardiac muscles, the loss of cardiomyocytes would eventually lead to compromised cardiac function. In the same way, loss of endothelial cells will lead to vascular dysfunction and aggravate the ischemia of the heart. Apoptot cardiomyocytes and endothelial cells have been observed it the heart of patient with diabetes and in STZ-induced diabetic rat (Cai \& Kang 2003, Adeghate 2004), ap to high glucose also induced the same two ty death in vitro (Detaille et al. 2005, Malhotr recent study showed that high gluce apoptosis of cultured lens epitheliz pathway. In diabetic heart, ER wa swollen by ultrastructural analysi in disorder in hyperglycem 1985, Bhimji et al. 1986, N hyperglycemia, the diabetio conditions that can store, increased 0 . such depressed ER Ca ${ }^{2+}$ lipid deposition ativy stess, hyp xia, hyperhomocysteine, (Gy thesis of secretory proteins (Ganguly 1991, Sicben ofer er al. 2003). Studies showed that UPR was induced in cardomyocytes in hypoxic conditions, and pressure overload by transverse aortic constriction also induced UPR associated with cardiomyocyte apoptosis (Okada et al. 2004). Moreover, cytokines (Cardozo et al. 2005) and norepinephrine (Mao et al. 2006), both of which play roles in the pathophysiology of diabetic cardiomyopathy, also induce UPR, suggesting that cardiomyocytes may be sensitive to ERS. All of the above results prompted us to examine whether ERS-specific apoptotic signaling is involved in diabetic rat heart.

The GRP78, also referred to as immunoglobulin heavy chain binding protein $(\mathrm{BiP})$, is a central regulator of $\mathrm{ER}$ function due to its foles rotein colding and assembly,
targeting misfol protein for degradation, ER $\mathrm{Ca}^{2+}$ binding, and contling the etivation of transmembrane ERS sensor. nnduction of GRP78 has been widely used as a marker for-ERS and the onset of UPR (Schröder \& Kaufman 2005. Fu hermore, Gi P78 serves as a master modulator for the $\mathrm{PR}$ net rork by binding to the ERS sensors such as protein kinase $\mathrm{R}$ (PKR)-like ER kinase, inositol requiring 1 (IRE), and ctivating transcription factor 6 (ATF6) and Thibiting their activation (Schröder \& Kaufman 2005).

apoptotic pathways, three are known to be related to The first is transcriptional induction of the gene for HOP; CHOP protein belongs to the C/EBP family of ranscription factors. It is commonly accepted that CHOP/ GADD153 expression is under the control of ATF6 and IRE1 signalings (Wang et al. 1998, Yoshida et al. 2000). Overexpression of $\mathrm{CHOP}$ promotes apoptosis, and deficiency of CHOP can protect cells from ERS-induced apoptosis (Zinszner et al. 1998, Oyadomari et al. 2002), suggesting that $\mathrm{CHOP}$ is involved in the process of cell death caused by ERS, and overexpression of CHOP sensitized the cells to ERS via down-regulation of proto-onco gene Bcl-2 expression. The second is the activation of caspase12. The ERS leads to increase in cytosolic calcium levels that induce the activation of $\mathrm{m}$-calpain. Activated
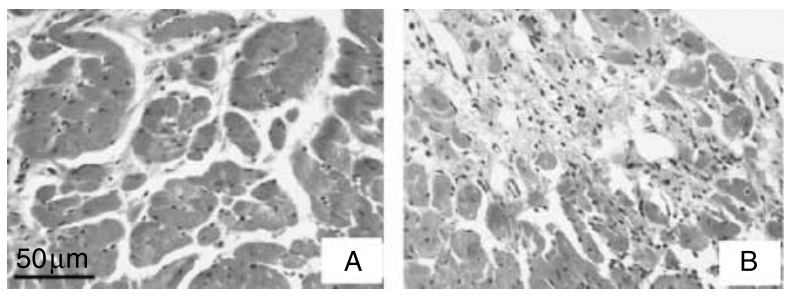

Figure 2 (A) The normal and (B) diabetic myocardium were stained with hematoxylin-eosin. Diabetic cardiac muscle fibers were disordered and many of them had collapsed. Diabetic myocardium showed fibrosis and extensive focal coalescent areas of ischemic myocyte degeneration in the subendocardial, subepicardial region, and papillary muscles of the myocardium. Bar $=50 \mu \mathrm{m}$. 


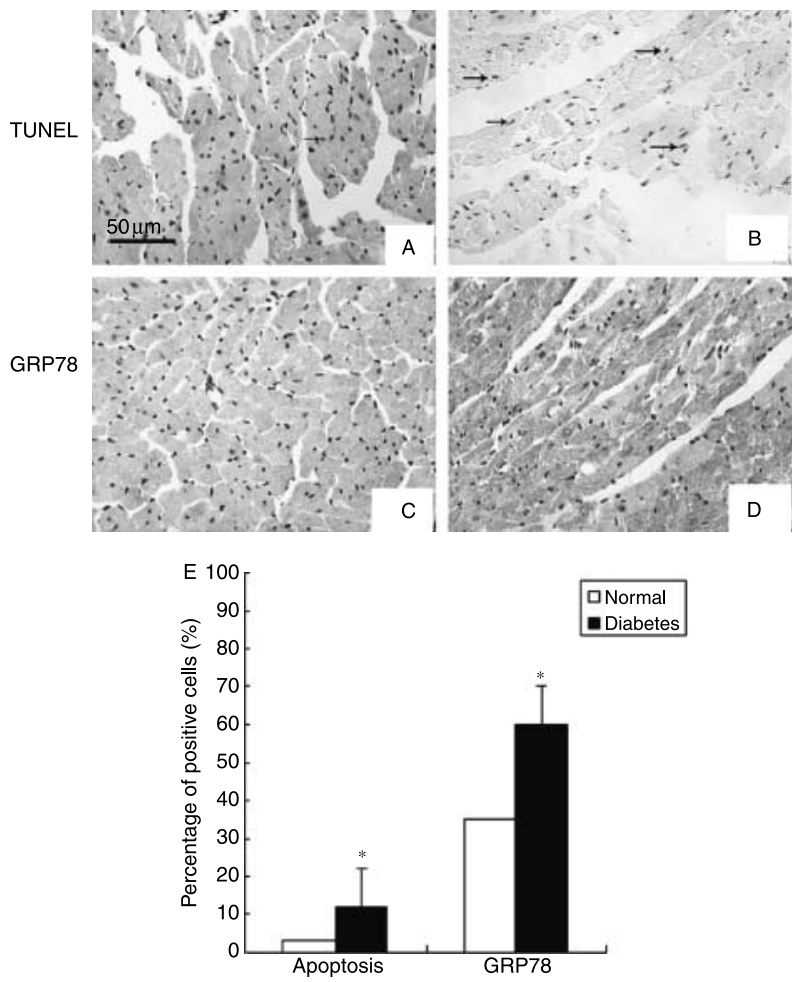

Figure 3 TUNEL staining of apoptotic bodies (pointed by arrow and IHC staining of GRP78 in (A and C) normal and (B and D diabetic rat myocardium. When compared with the normal he the diabetic heart has significantly (E) higher positive expressio $* P<0 \cdot 05$ versus normal rat. Bar $=50 \mu \mathrm{m}$.

m-calpain cleaves $\mathrm{Bcl}-\mathrm{X}_{\mathrm{L}}$ and proteolytic pase12. Processed-caspase12 reported ty ctivtes caspase9, followed by activation of caspase 3 (B al. 2002). Na agawa et al. (2000) demonstrated that caspasediated apoptosis was a specific apoptotic path of ER and apoptosis that occurred as a result of men me or mito - ondrial-targeted signals did not activate it caspas 12 knockout mice exhibit resistance to ERS, suggesting the cas 12 also plays a role in the process of cell death aused by $\mathrm{S}$. The third is activation of the JNK pathy (crano et o. 2000) that is mediated by formation of the TRE-tumor necrosis factor receptorassociated factor -ap posis snal-regulating kinase 1 complex. Activation of JNK is a common response to many forms of stress and is known to influence the cell-death machinery through the regulation of BCL2 family proteins (Davis 2000). Phosphorylation of BCL2 by JNK, which occurs primarily at the ER, suppresses the anti-apoptotic activity of BCL2. Of the three components of the ER-related death pathways, induction of $\mathrm{CHOP}$ and activation of caspase 12 are ER-specific pathways. Therefore, we used these two pathways as markers of induction of the ER-specific death pathway, and also examined the JNK pathway. In the present study, the increased induction of GRP78, CHOP, cleavage of caspase12, and JNK in diabetic rat myocardium paralleled with the increased apoptotic cells. These
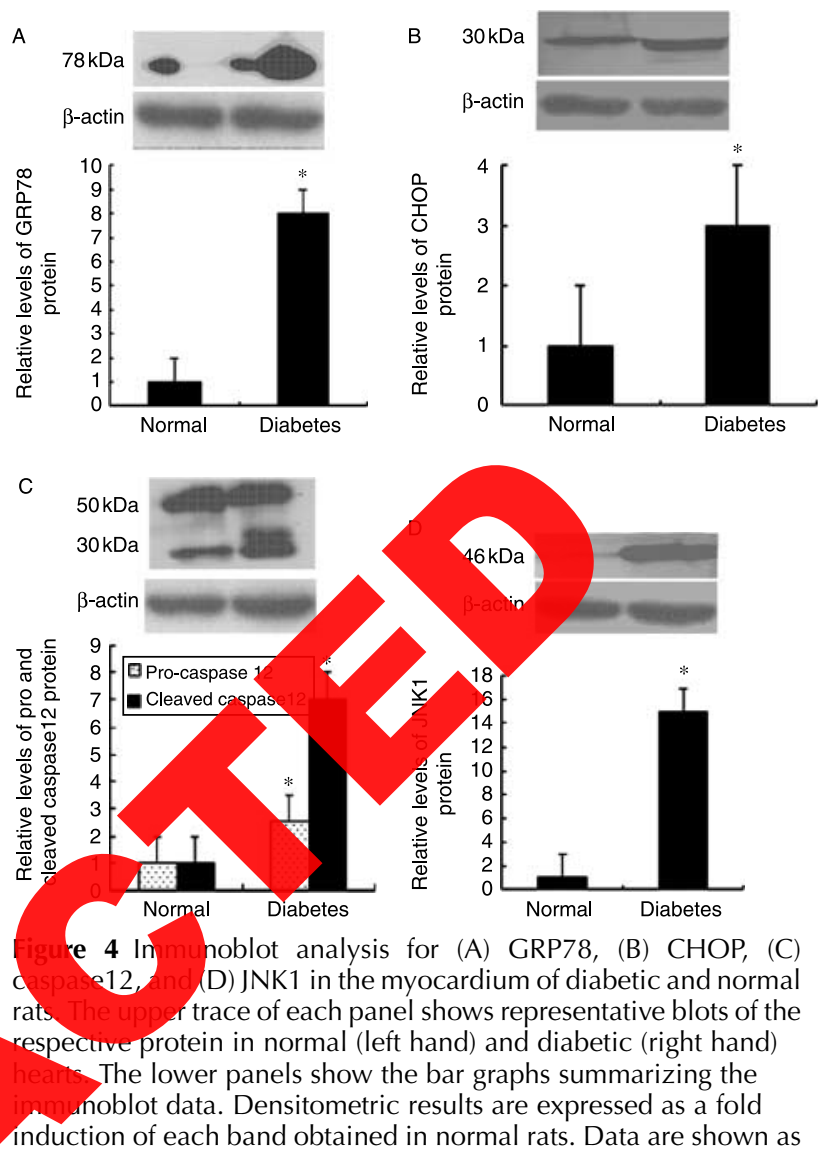

mean \pm s.D. ${ }^{*} P<0 \cdot 05$ versus normal rat.

findings indicate that a hyperglycemia environment induce ER-dependent death pathway activity, leading to apoptosis.

To our knowledge, in normal heart, synthesis of secretory proteins is not a major function of a cardiac myocyte, but with the development of cardiomyopathy in diabetes, the heart could become a neuroendocrine organ attributed to

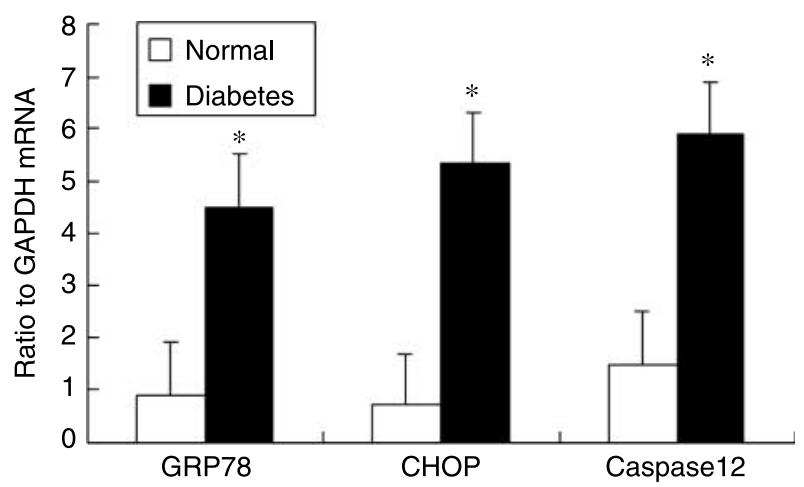

Figure 5 Total RNA was extracted from myocardium and subjected to real-time PCR quantification as described under Materials and Methods. Values represent the ratio to GAPDH mRNA that is arbitrarily defined as 1 . Data are shown as mean \pm s.D. ${ }^{*} P<0 \cdot 05$ versus normal rat. 
prolonged elevation of protein synthesis such as atrial natriuretic peptide and brain natriuretic peptide (Howarth et al. 2006, Obineche et al. 2006) and together with other strong inducers we suggested in the introduction that the ERS may participate in the beginning of diabetic cardiomyopathy. Compared with other mechanisms, involved in the diabetic myocardial cell, ERS may have crosstalk with them; this means that ERS is not only parallel with them but also as a result and mediator for other ways to apoptosis. For example, increased ROS derived from hyperglycemia has been considered the most important reason for cell death, because it can cause abnormal gene expression, altered signal transduction, and it is also involved in the activation of the UPR on exposure to oxidative stress, which is an adaptive mechanism to preserve cell function and survival, but persistent oxidative stress and protein misfolding initiate apoptotic cascades which then lead to cell death.

In summary, this study provides the first evidence of GRP78 increase, and that the three pathways of ERSinduced apoptosis are activated in the diabetic heart. Our findings suggest that ER-initiated apoptosis may contribute to diabetic cardiomyopathy, and further investigation about the intracellular signaling and the weight of ERS-induced apoptosis in diabetic cardiomyopathy will be required. downregulate the sarcoendoplasmic reticulum pump $\mathrm{Ca}^{2+}$ ATPase $2 \mathrm{~b}$ and deplete endoplasmic reticulum $\mathrm{Ca}^{2+}$, leading to induction of endoplasmic reticulum stress in pancreatic beta-cells. Diabetes $\mathbf{5 4} 452-461$.

Choi KM, Zhong Y, Hoit BD, Grupp IL, Hahn H, Dilly KW, Guatimosim S, Lederer WJ \& Matlib MA 2002 Defective intracellular $\mathrm{Ca}(2+)$ signaling contributes to cardiomyopathy in Type 1 diabetic rats. American Journal of Physiology, Heart and Circulatory Physiology 283 H1398-H1408.

Davis RJ 2000 Signal transduction by the JNK group of MAP kinases. Cell 103 239-252.

Detaille D, Guigas B, Chauvin C, Batandier C, Fontaine E, Wiernsperger N \& Leverve X 2005 Metformin prevents high-glucose-induced endothelial cell death through a mitochondrial permeability transition-dependent process. Diabetes 54 2179-2187.

Dyntar D, Sergeev P, Klisic J, Ambuhl P, Schaub MC \& Donath MY 2006 High glucose alters cardiomyocyte contacts and inhibits myofibrillar formation. Journal of Clinical Endocrinology Metadism 91 1961-1967.

Ferri KF \& Kroemer G 2001 Organelle-s. pathways. Nature Cell Biology 3 E255

Feuvray D 2004 Diabetic cardiomyo Vaisseaux 97 261-265.

Galderisi M 2006 Diastolic evaluation by Doppler e Cardiology 48 1548-1

Ganguly PK 1991 R due to chronic

Ghosh S \& R modulation

Hayd MR Tyagi SC, Kerko MM \& Nicolls MR 2005 Type 2 diabetes $\mathrm{n}$ elli us as a controtional disease. Journal of the Pancreas 6 287-302.

Het C, Russelak arneiro M, Maundrell K, Castilla J \& Soto C 2003 Ca doperasmic reticulum stress mediate neurotoxicity of pathological pyon protein. EMBO Journal 22 5435-5445.

thmisligil GS 2005 Role of endoplasmic reticulum stress and c-Jun minal kinase pathways in inflammation and origin of obesity and s. Diabetes 54 (Suppl 2) S73-S78.

owarth FC, Al-Shamsi N, Al-Qaydi M, Al-Mazrouei M, Qureshi A, Chandranath SI, Kazzam E \& Adem A 2006 Effects of brain natriuretic peptide on contraction and intracellular $\mathrm{Ca}^{2+}$ in ventricular myocytes from the streptozotocin-induced diabetic rat. Annals of the New York Academy of Sciences 1084 155-165.

Jackson CV, McGrath GM, Tahiliani AG, Vadlamudi RV \& McNeill JH 1985 A functional and ultrastructural analysis of experimental diabetic rat myocardium. Manifestation of a cardiomyopathy. Diabetes 34 876-883.

King GL \& Loeken MR 2004 Hyperglycemia-induced oxidative stress in diabetic complications. Histochemistry and Cell Biology 122 333-338.

Ligeti L, Szenczi O, Prestia CM, Szabo C, Horvath K, Marcsek ZL, van Stiphout RG, van Riel NA, Op den Buijs J, Van der Vusse GJ et al. 2006 Altered calcium handling is an early sign of streptozotocin-induced diabetic cardiomyopathy. International Journal of Molecular Medicine 17 1035-1043.

Malhotra A, Kang BP, Hashmi S \& Meggs LG 2005 PKCepsilon inhibits the hyperglycemia-induced apoptosis signal in adult rat ventricular myocytes. Molecular and Cellular Biochemistry 268 169-173.

Mao W, Iwai C, Keng PC, Vulapalli R \& Liang CS 2006 Norepinephrineinduced oxidative stress causes PC-12 cell apoptosis by both endoplasmic reticulum stress and mitochondrial intrinsic pathway: inhibition of phosphatidylinositol 3-kinase survival pathway. American Journal of Physiology, Cell Physiology 290 C1373-C1384.

Mulhern ML, Madson CJ, Danford A, Ikesugi K, Kador PF \& Shinohara T 2006 The unfolded protein response in lens epithelial cells from galactosemic rat lenses. Investigative Ophthalmology and Visual Science 47 3951-3959.

Nakagawa T, Zhu H, Morishima N, Li E, Xu J, Yankner BA \& Yuan J 2000 Caspase-12 mediates endoplasmic-reticulum-specific apoptosis and cytotoxicity by amyloid-beta. Nature $\mathbf{4 0 3} 98-103$.

Nakatani Y, Kaneto H, Kawamori D, Yoshiuchi K, Hatazaki M, Matsuoka TA, Ozawa K, Ogawa S, Hori M, Yamasaki Y et al. 2005 Involvement of endoplasmic reticulum stress in insulin resistance and diabetes. Journal of Biological Chemistry 280 847-851. 
Obineche E, Chandranath I, Adeghate E, Benedict S, Fahim M \& Adem A 2006 Alterations in atrial natriuretic peptide and its receptor levels in longterm, streptozotocin-induced, diabetes in rats. Annals of the New York Academy of Sciences 1084 223-234.

Okada K, Minamino T, Tsukamoto Y, Liao Y, Tsukamoto O, Takashima S, Hirata A, Fujita M, Nagamachi Y, Nakatani T et al. 2004 Prolonged endoplasmic reticulum stress in hypertrophic and failing heart after aortic constriction: possible contribution of endoplasmic reticulum stress to cardiac myocyte apoptosis. Circulation 110 705-712.

Oyadomari S, Koizumi A, Takeda K, Gotoh T, Akira S, Araki E \& Mori M 2002 Targeted disruption of the Chop gene delays endoplasmic reticulum stress-mediated diabetes. Journal of Clinical Investigation 109 525-532.

Pang Y, Hunton DL, Bounelis P \& Marchase RB 2002 Hyperglycemia inhibits capacitative calcium entry and hypertrophy in neonatal cardiomyocytes. Diabetes 51 3461-3467.

Pereira L, Matthes J, Schuster I, Valdivia HH, Herzig S, Richard S \& Gomez AM 2006 Mechanisms of $\left[\mathrm{Ca}^{2+}\right]_{\mathrm{i}}$ transient decrease in cardiomyopathy of $\mathrm{db} / \mathrm{db}$ type 2 diabetic mice. Diabetes $\mathbf{5 5}$ 608-615.

Picano E 2003 Diabetic cardiomyopathy: the importance of being earliest. Journal of the American College of Cardiology 42 454-457.

Rao RV, Castro-Obregon S, Frankowski H, Schuler M, Stoka V, del Rio G, Bredesen DE \& Ellerby HM 2002 Coupling endoplasmic reticulum stress to the cell death program. An Apaf-1-independent intrinsic pathway. Journal of Biological Chemistry 277 21836-21842.

Riggs AC, Bernal-Mizrachi E, Ohsugi M, Wasson J, Fatrai S, Welling C, Murray J, Schmidt RE, Herrera PL \& Permutt MA 2005 Mice conditionally lacking the Wolfram gene in pancreatic islet beta cells exhibit diabetes as a result of enhanced endoplasmic reticulum stress and apoptosis. Diabetologia 48 2313-2321.

Schröder M \& Kaufman RJ 2005 The mammalian unfolded protein response. Annual Review of Biochemistry 74 739-789.

Siebenhofer A, Ng LL, Plank J, Berghold A, Hodl R \& Pieber TR 2003 Plasma N-terminal pro-brain natriuretic peptide in Type 1 diabetic patie with and without diabetic nephropathy. Diabetic Medicine 20 535-53

Tappia PS, Asemu G, Aroutiounova N \& Dhalla NS 2004 Defective sarcolemmal phospholipase $\mathrm{C}$ signaling in diabetic cardiomyopathy. Molecular and Cellular Biochemistry 261 193-199.
Tiwari M, Kumar A, Sinha RA, Shrivastava A, Balapure AK, Sharma R, Bajpai VK, Mitra K, Babu S \& Godbole MM 2006 Mechanism of 4-HPRinduced apoptosis in glioma cells: evidences suggesting role of mitochondrial-mediated pathway and endoplasmic reticulum stress. Carcinogenesis 27 2047-2058.

Urano F, Wang X, Bertolotti A, Zhang Y, Chung P, Harding HP \& Ron D 2000 Coupling of stress in the ER to activation of JNK protein kinases by transmembrane protein kinase IRE1. Science 287 664-666.

Wang XZ, Lawson B, Brewer JW, Zinszner H, Sanjay A, Mi LJ, Boorstein R, Kreibich G, Hendershot LM \& Ron D 1996 Signals from the stressed endoplasmic reticulum induce $\mathrm{C} / \mathrm{EBP}$-homologous protein (CHOP/GADD153). Molecular and Cellular Biology 16 4273-4280.

Wang XZ, Harding HP, Zhang Y, Jolicoeur EM, Kuroda M \& Ron D 1998 Cloning of mammalian Ire1 reveals diversity in the ER stress responses. EMBO Journal 17 5708-5717.

Werstuck GH, Khan MI, Femia G, Kim 2006 Glucosamine-induced endopl ated with accelerated atherosclero Diabetes 55 93-101.

Wijekoon EP, Brosnan ME \& diabetes. Biochemical So

Yoshida H, Okada T, $\mathrm{H}$ ATF6 activated b. to the cis-action response. $M$

ment re and Cellula

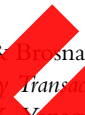
reticulum Tysunction is associhypergy cen ic mouse model.

Zinszner K. Kư Stevens JL \& Ron 199 CHOP is implicated in programmed cell death in spons to impaired cion of the endoplasmic reticulum. Genes and elopment 12 982-995.

Received in final form 23 November 2007

ccepted 13 December 2007 available online as an Accepted Preprint 13 December 2007 